\title{
Molecular Dynamics \\ Simulations of Matrix Metalloproteinase 2: \\ The Role of the Structural Metal Ions
}

\author{
Natalia Díaz* and Dimas Suárez \\ diazfnatalia@uniovi.es \\ SUPPORTING MATERIAL
}

\section{Parameterization of the zinc ions}

There are two basic ways to model metal ions using a purely classical potential function: the bonded model(61) and the nonbonded model.(62, 63) Preliminary MD calculations (not reported here) showed that the nonbonded representation for the zinc ions in the MMP-2 enzyme systematically gives rise to octahedrally-coordinated metals, as previously reported by other authors.(64, 65) However, in the MMPs, $\mathrm{Zn}_{2}$ invariably adopts a tetrahedral coordination geometry.(66) For the catalytic $\mathrm{Zn}_{1}$ ion, we found that a trigonal bipyramid geometry is the most stable one in the active form of the enzyme as predicted by DFT/MM calculations. (67)

On the basis of all the previous experimental and computational data, we adopted a bonded approach for the $\mathrm{Zn}_{2}$ ion by placing explicit bonds between the metal ion and the $\mathrm{His}_{178}-\mathrm{N} \varepsilon$, Asp $_{180}-\mathrm{O} \delta$, His ${ }_{193}-\mathrm{N} \varepsilon$, and $\mathrm{His}_{206}-\mathrm{N} \delta$ atoms. For $\mathrm{Zn}_{1}$ we implemented a mixed bonded \& nonbonded representation in which the metal ion is linked to the $\mathrm{His}_{403}-\mathrm{N} \varepsilon, \mathrm{His}_{408}-\mathrm{N} \varepsilon, \mathrm{His}_{413}-\mathrm{N} \varepsilon$ atoms and the bridging $\left[\mathrm{Zn}-\left(\mathrm{OH}_{2}\right)\right]^{2+} . .{ }^{-} \mathrm{OOC}-\mathrm{Glu}_{404}$ water molecule by explicit MM bonds, while a second water molecule coordinated to the metal is represented by the standard non- 
bonded parameters. This mixed description seems best suited for describing the important $\left[\mathrm{Zn}-\left(\mathrm{OH}_{2}\right)\right]^{2+}{ }^{-.}{ }^{-} \mathrm{OOC}-\mathrm{Glu}_{404}$ interaction and, simultaneously, allows solvent exchange at the apical position.

Initial geometries (bond lengths and angles) for the $\mathrm{Zn}_{1}$ and $\mathrm{Zn}_{2}$ coordination spheres were obtained from QM/MM energy minimizations performed with the program QSite(68) as described elsewhere.(67) From these structures, we extracted a cluster model of the $\mathrm{Zn}_{1}$ and $\mathrm{Zn}_{2}$ coordination spheres, including the side chains of $\mathrm{His}_{178}, \mathrm{Asp}_{180}$, His ${ }_{193}$, and His $\mathrm{H}_{206}$ for $\mathrm{Zn}_{2}$, and $\mathrm{His}_{403}, \mathrm{Glu}_{404}, \mathrm{His}_{408}$, His 413 and two water molecules for $\mathrm{Zn}_{1}$. Then, we estimated numerically the force constants for the bond (Zn-X) and angle (Zn-X-Y and X-Zn-Y) MM terms by performing gradient calculations at the original geometry of the cluster model and at a geometry for which the corresponding internal coordinate was changed slightly. These QM calculations were carried out at the B3LYP/LACVP* level of theory(69) using the JAGUAR program.(70) All the torsions associated with the zinc-ligand interactions were set to zero.

Starting from the cluster models of $\mathrm{Zn}_{1}$ and $\mathrm{Zn}_{2}$, we derived atomic partial charges using the RESP methodology(71) at the B3LYP/LACVP* level of theory. During the RESP fitting procedure, we assigned a zero value to the atomic charges of the H-link atoms. We also imposed the TIP3P charges for the apical water molecule bound to $\mathrm{Zn}_{1}$ and a global charge of $-0.8822 e$ for the $\mathrm{Glu}_{404}$ side chain. In this way, we made sure that electrostatic interactions between all atoms of the enzymatic system are treated on an equal basis, thereby minimizing partial charge artefacts. To preserve the integral charge of the whole system, the partial charges of the backbone atoms of the residues bound to $\mathrm{Zn}_{1}$ and $\mathrm{Zn}_{2}$ were slightly modified. 
The van der Waals parameters for the $\mathrm{Zn}_{2}$ ion were taken from Hoops et. al.(61) because these parameters were developed for representing tetrahedral zinc complexes within the bonded approach. As above mentioned, we adopted a mixed bonded \& nonbonded approach for $\mathrm{Zn}_{1}$ and, accordingly, the van der Waals $\varepsilon$-parameter was assigned an intermediate value between those of the bonded and the non-bonded representations. We also assigned non-zero van der Waals parameters to the hydrogen atoms of the $\mathrm{Zn}_{1}$ bound water molecule (W1) to properly reproduce the $\mathrm{Zn}_{1}-\mathrm{OH}_{2} \cdots^{-} \mathrm{OOC}-\mathrm{Glu}_{404}$ distance. The rest of the atoms in the water and imidazole rings were assigned the corresponding standard AMBER atom types.

The force field parametrization was tested by performing energy minimizations and short MD simulations of the MMP-2 $\mathbf{C a}_{\mathbf{1 - 2}} \mathbf{\&} \mathbf{Z n}_{\mathbf{1 - 2}}$ configuration showing that the geometrical parameters describing the zinc coordination spheres during the MD simulation remain close to their $\mathrm{QM} / \mathrm{MM}$ reference values. All the parameters used to represent the $\mathrm{Zn}_{1}$ and $\mathrm{Zn}_{2}$ environments are available from the authors upon request. 
Table S1. Ca-L distances (in $\AA$ ) corresponding to the calcium ions modelled in the MMP-2 catalytic domain and the protein residues that coordinate them. The range of the Ca-L experimental values, as obtained from the available tridimensional structures, is also included.

\begin{tabular}{|c|c|c|c|c|c|c|c|c|c|}
\hline & Experimental values $^{\mathrm{a}}$ & $\mathrm{Ca}_{1-3} \& \mathrm{Zn}_{1-2}$ & $\mathrm{Ca}_{1-2} \& \mathrm{Zn}_{1-2}$ & $\mathrm{Ca}_{2} \& \mathrm{Zn}_{1-2}$ & $\mathrm{Ca}_{1} \& \mathrm{Zn}_{1-2}$ & $\mathbf{Z n}_{1-2}$ & $\mathrm{Ca}_{1-2} \& \mathrm{Zn}_{1}$ & $\mathbf{Z n}_{1}$ & $\mathrm{Ca}_{1-2} \& \mathrm{Zn}_{1-2}$-Fibronectin \\
\hline & \multicolumn{9}{|c|}{$\mathbf{C a}_{1}$} \\
\hline $\operatorname{Asp}_{185} \mathbf{O}$ & $2.9-5.0$ & $5.91 \pm 0.36$ & $5.24 \pm 0.22$ & -- & $5.57 \pm 0.33$ & -- & $5.57 \pm 0.39$ & -- & $2.97 \pm 0.68$ \\
\hline $\operatorname{Asp}_{185} \mathbf{O} \delta$ & $2.4-3.8$ & $2.59 \pm 0.09$ & $3.11 \pm 0.80$ & -- & $3.12 \pm 0.74$ & -- & $2.65 \pm 0.10$ & -- & $2.58 \pm 0.07$ \\
\hline Gly $_{186}$ O & $2.2-2.6$ & $2.65 \pm 0.09$ & $2.70 \pm 0.10$ & -- & $2.65 \pm 0.09$ & -- & $2.67 \pm 0.09$ & -- & $2.65 \pm 0.08$ \\
\hline $\operatorname{Asp}_{188} \mathbf{O}$ & $2.2-2.9$ & $2.64 \pm 0.09$ & $2.69 \pm 0.11$ & -- & $2.67 \pm 0.10$ & -- & $2.65 \pm 0.09$ & -- & $2.65 \pm 0.09$ \\
\hline $\operatorname{Leu}_{190} O$ & $2.3-2.7$ & $2.68 \pm 0.09$ & $2.64 \pm 0.08$ & -- & $2.66 \pm 0.09$ & -- & $2.66 \pm 0.10$ & -- & $2.68 \pm 0.09$ \\
\hline $\operatorname{Asp}_{208} \mathbf{O} \delta$ & $2.3-3.1$ & $2.55 \pm 0.07$ & $2.60 \pm 0.08$ & -- & $2.57 \pm 0.07$ & -- & $2.56 \pm 0.07$ & -- & $2.53 \pm 0.06$ \\
\hline \multirow[t]{2}{*}{$\mathbf{G l u}_{211} \mathbf{O} \varepsilon$} & $2.3-2.8$ & $2.56 \pm 0.08$ & $2.54 \pm 0.06$ & -- & $2.55 \pm 0.07$ & -- & $2.56 \pm 0.07$ & -- & $2.55 \pm 0.07$ \\
\hline & \multicolumn{9}{|c|}{$\mathrm{Ca}_{2}$} \\
\hline Glu $_{166} O \varepsilon$ & $3.2-5.0$ & $6.81 \pm 1.23$ & $2.62 \pm 0.08$ & $2.61 \pm 0.08$ & -- & -- & $2.62 \pm 0.09$ & -- & $2.61 \pm 0.08$ \\
\hline $\operatorname{Ala}_{167} \mathrm{O}$ & $2.9-4.0$ & $2.82 \pm 0.17$ & $2.70 \pm 0.10$ & $2.69 \pm 0.09$ & -- & -- & $2.68 \pm 0.09$ & -- & $2.69 \pm 0.09$ \\
\hline $\operatorname{Asp}_{168} \mathrm{O}$ & $2.5-3.2$ & $2.74 \pm 0.12$ & $2.79 \pm 0.14$ & $2.79 \pm 0.14$ & -- & -- & $2.80 \pm 0.14$ & -- & $2.77 \pm 0.13$ \\
\hline Gly $_{200} \mathrm{O}$ & $2.5-3.2$ & $2.66 \pm 0.09$ & $2.65 \pm 0.09$ & $2.65 \pm 0.08$ & -- & -- & $2.66 \pm 0.09$ & -- & $2.64 \pm 0.08$ \\
\hline Gly $_{202} \mathrm{O}$ & $2.5-3.7$ & $2.74 \pm 0.11$ & $2.72 \pm 0.10$ & $2.71 \pm 0.10$ & -- & -- & $2.74 \pm 0.11$ & -- & $2.72 \pm 0.10$ \\
\hline \multirow[t]{2}{*}{$\operatorname{Asp}_{204} \mathbf{O} \delta$} & $2.6-4.9$ & $2.58 \pm 0.07$ & $2.56 \pm 0.07$ & $2.56 \pm 0.06$ & -- & -- & $2.57 \pm 0.07$ & -- & $2.56 \pm 0.06$ \\
\hline & \multicolumn{9}{|c|}{$\mathrm{Ca}_{3}$} \\
\hline $\operatorname{Asp}_{134} \mathbf{O} \delta 1$ & 3.0 & $2.67 \pm 0.14$ & -- & -- & -- & -- & -- & -- & -- \\
\hline $\mathbf{A s p}_{134} \mathbf{O} \delta 2$ & 2.6 & $2.69 \pm 0.17$ & -- & -- & -- & -- & -- & -- & -- \\
\hline $\operatorname{Asp}_{209} \mathbf{O}$ & 2.7 & $2.70 \pm 0.12$ & -- & -- & -- & -- & -- & -- & -- \\
\hline $\operatorname{Asp}_{209} \mathbf{O} \delta$ & 2.8 & $4.34 \pm 0.89$ & -- & -- & -- & -- & -- & -- & -- \\
\hline Glu $_{211} \mathrm{O}$ & 2.5 & $2.66 \pm 0.09$ & -- & -- & -- & -- & -- & -- & -- \\
\hline
\end{tabular}

${ }^{\mathrm{a}}$ Values obtained from the MMP-2 tridimensional structures (PDB codes: 1CK7, 1EAK, 1QIB, 1GXD and 1HOV). 
Table S2. RMSD and RMSF values for the MD Simulations of the Catalytic Domain of MMP-2.

\begin{tabular}{|c|c|c|c|c|c|c|c|c|}
\hline & $\mathrm{Ca}_{1-3} \& \mathrm{Zn}_{1-2}$ & $\mathrm{Ca}_{1-2} \& \mathrm{Zn}_{1-2}$ & $\mathrm{Ca}_{2} \& \mathrm{Zn}_{1-2}$ & $C a_{1} \& Z n_{1-2}$ & $\mathbf{Z n}_{1-2}$ & $\mathrm{Ca}_{1-2} \& \mathrm{Zn}_{1}$ & $\mathbf{Z n}_{1}$ & $\mathrm{Ca}_{1-2} \& \mathrm{Zn}_{1-2}$ Fibronectin $^{\mathrm{b}}$ \\
\hline & \multicolumn{8}{|c|}{ RMSD (Å) } \\
\hline All $^{a}$ & $2.12 \pm 0.16$ & $1.80 \pm 0.10$ & $2.08 \pm 0.14$ & $2.57 \pm 0.24$ & $2.58 \pm 0.16$ & $2.58 \pm 0.14$ & $2.62 \pm 0.31$ & $1.78 \pm 0.17^{\mathrm{b}}$ \\
\hline Back $^{\text {a }}$ & $1.63 \pm 0.14$ & $1.41 \pm 0.11$ & $1.65 \pm 0.15$ & $2.34 \pm 0.26$ & $2.31 \pm 0.18$ & $2.18 \pm 0.16$ & $2.18 \pm 0.30$ & $1.21 \pm 0.12^{\mathrm{b}}$ \\
\hline Helix $\alpha 2$ & $0.36 \pm 0.04$ & $0.37 \pm 0.04$ & $0.39 \pm 0.05$ & $0.38 \pm 0.05$ & $0.35 \pm 0.04$ & $0.39 \pm 0.05$ & $0.38 \pm 0.05$ & $0.39 \pm 0.05$ \\
\hline Strand $\beta 4$ & $0.24 \pm 0.06$ & $0.24 \pm 0.06$ & $0.29 \pm 0.07$ & $0.28 \pm 0.10$ & $0.29 \pm 0.08$ & $0.30 \pm 0.07$ & $0.30 \pm 0.08$ & $0.25 \pm 0.06$ \\
\hline Zn/Ca S loop & $2.04 \pm 0.35$ & $1.20 \pm 0.11$ & $1.55 \pm 0.22$ & $1.28 \pm 0.16$ & $1.37 \pm 0.11$ & $2.28 \pm 0.28$ & $2.85 \pm 0.92$ & $1.10 \pm 0.14$ \\
\hline$\beta 4-\beta 5$ loop & $0.66 \pm 0.11$ & $0.63 \pm 0.10$ & $0.60 \pm 0.11$ & $1.38 \pm 0.14$ & $1.27 \pm 0.18$ & $0.68 \pm 0.14$ & $1.34 \pm 0.20$ & $0.59 \pm 0.12$ \\
\hline \multirow[t]{2}{*}{$\Omega$ loop } & $1.18 \pm 0.13$ & $0.88 \pm 0.11$ & $1.25 \pm 0.13$ & $1.15 \pm 0.20$ & $1.10 \pm 0.16$ & $1.24 \pm 0.09$ & $0.94 \pm 0.16$ & $1.06 \pm 0.19$ \\
\hline & \multicolumn{8}{|c|}{ RMSF (Å) } \\
\hline All $^{a}$ & $1.08 \pm 0.08$ & $0.96 \pm 0.09$ & $1.10 \pm 0.12$ & $1.17 \pm 0.16$ & $1.17 \pm 0.20$ & $1.22 \pm 0.23$ & $1.43 \pm 0.18$ & $1.02 \pm 0.10$ \\
\hline Back $^{\text {a }}$ & $0.74 \pm 0.08$ & $0.69 \pm 0.08$ & $0.83 \pm 0.11$ & $0.94 \pm 0.17$ & $0.92 \pm 0.22$ & $0.99 \pm 0.25$ & $1.14 \pm 0.17$ & $0.73 \pm 0.08$ \\
\hline Helix $\alpha 2$ & $0.23 \pm 0.04$ & $0.24 \pm 0.04$ & $0.24 \pm 0.04$ & $0.24 \pm 0.05$ & $0.24 \pm 0.04$ & $0.24 \pm 0.04$ & $0.25 \pm 0.05$ & $0.25 \pm 0.04$ \\
\hline Strand $\beta 4$ & $0.18 \pm 0.06$ & $0.19 \pm 0.08$ & $0.17 \pm 0.06$ & $0.26 \pm 0.10$ & $0.24 \pm 0.10$ & $0.21 \pm 0.08$ & $0.27 \pm 0.09$ & $0.18 \pm 0.07$ \\
\hline Zn/Ca S loop & $0.84 \pm 0.21$ & $0.46 \pm 0.13$ & $0.82 \pm 0.18$ & $0.50 \pm 0.15$ & $0.60 \pm 0.14$ & $0.91 \pm 0.24$ & $1.78 \pm 0.27$ & $0.50 \pm 0.21$ \\
\hline$\beta 4-\beta 5$ loop & $0.32 \pm 0.08$ & $0.32 \pm 0.07$ & $0.36 \pm 0.09$ & $0.77 \pm 0.22$ & $0.77 \pm 0.20$ & $0.35 \pm 0.09$ & $0.47 \pm 0.15$ & $0.33 \pm 0.09$ \\
\hline$\Omega$ loop & $0.61 \pm 0.12$ & $0.62 \pm 0.13$ & $0.74 \pm 0.14$ & $0.69 \pm 0.14$ & $0.71 \pm 0.17$ & $0.52 \pm 0.10$ & $0.65 \pm 0.14$ & $0.85 \pm 0.13$ \\
\hline
\end{tabular}

${ }^{\mathrm{a}}$ Without including the random $N$-terminal coil (residues $\mathrm{Asn}_{111}-\mathrm{Asn}_{122}$ )
${ }^{\mathrm{b}}$ Without including the three fibronectin domains

c X-ray value (1CK7) $14.8 \AA$. 
Table S3. Radius of gyration and Solvent Accessible Surface Area (SASA) values for the MD Simulations of the Catalytic Domain of MMP-2.

\begin{tabular}{|c|c|c|c|c|c|c|c|c|}
\hline & $C a_{1-3} \& Z_{1-2}$ & $\mathrm{Ca}_{1-2} \& \mathrm{Zn}_{1-2}$ & $\mathbf{C a}_{2} \& \mathbf{Z n}_{1-2}$ & $\mathrm{Ca}_{1} \& \mathbf{Z n}_{1-2}$ & $\mathbf{Z n}_{1-2}$ & $\mathrm{Ca}_{1-2} \& \mathbf{Z n}_{1}$ & $\mathbf{Z n}_{1}$ & $\begin{array}{l}\mathrm{Ca}_{1-2} \& \mathrm{Zn}_{1-2} \\
\text { Fibronectin }\end{array}$ \\
\hline & & & & Radius of & $\operatorname{ation}^{\mathrm{a}}(\AA)$ & & & \\
\hline \multirow[t]{2}{*}{ All } & $15.28 \pm 0.06$ & $15.24 \pm 0.05$ & $15.27 \pm 0.07$ & $15.42 \pm 0.06$ & $15.53 \pm 0.08$ & $15.54 \pm 0.14$ & $15.48 \pm 0.10$ & $15.05 \pm 0.06^{\mathrm{b}}$ \\
\hline & \multicolumn{8}{|c|}{$\operatorname{SASA}\left(\AA^{2}\right)$} \\
\hline All & $9261 \pm 137$ & $9223 \pm 124$ & $9181 \pm 157$ & $9669 \pm 105$ & $9455 \pm 172$ & $9738 \pm 153$ & $9548 \pm 184$ & $7882 \pm 159^{b}$ \\
\hline $\operatorname{Trp}_{119}$ & $11 \pm 5$ & $15 \pm 8$ & $16 \pm 6$ & $29 \pm 6$ & $16 \pm 16$ & $20 \pm 5$ & $8 \pm 6$ & -- \\
\hline $\operatorname{Trp}_{151}$ & $0 \pm 0$ & $0 \pm 4$ & $0 \pm 0$ & $0 \pm 0$ & $0 \pm 0$ & $0 \pm 0$ & $0 \pm 0$ & -- \\
\hline $\operatorname{Trp}_{176}$ & $177 \pm 13$ & $135 \pm 15$ & $118 \pm 22$ & $186 \pm 17$ & $132 \pm 16$ & $74 \pm 23$ & $134 \pm 33$ & -- \\
\hline $\operatorname{Trp}_{213}$ & $1 \pm 1$ & $8 \pm 7$ & $10 \pm 8$ & $5 \pm 4$ & $5 \pm 3$ & $14 \pm 9$ & $13 \pm 9$ & -- \\
\hline
\end{tabular}

${ }^{\mathrm{a}}$ X-ray value (1CK7) $14.8 \AA$.

${ }^{\mathrm{b}}$ Without including the three fibronectin domains 


\section{Validation calculations on cluster models of the $\mathrm{Ca}_{1}$ and $\mathrm{Ca}_{2}$ sites}

In principle, the relative energetic stability of the different MMP-2 configurations is governed by several factors (e.g., the strength of metal-protein bonds; protein-solvent interactions; long range protein-protein interactions, etc.) that can be taken into account by means of semiempirical PM3-PBSA calculations. To better calibrate the performance of the semiempirical QM Hamiltonian (PM3), we examined a formal $\mathrm{Ca}^{2+}$ exchange process between two cluster models ( 200 atoms) of the $\mathrm{Ca}_{1}$ and $\mathrm{Ca}_{2}$ sites in the MMP-2 enzyme using DFT and PM3 methodologies (Table S4 and Figure S1).

The cluster models consisted of 12 residues located within a distance of $\sim 10 \AA$ to the $\mathrm{Ca}_{1}$ and $\mathrm{Ca}_{2}$ atoms in the $1 \mathrm{CK} 7 \mathrm{X}$-ray structure, respectively. Terminal $N$-methylamine or acetyl groups were placed at the $\mathrm{C}$ and $\mathrm{N}$ backbone atoms of those residues cut out from the protein main chain by the truncation process. The semiempirical QM energies of the cluster models were computed by performing single-point PM3 calculations in solution using DIVCON. The DFT energies were obtained using the TURBOMOLE suite of programs.(72) We employed the PBE functional(73) combined with a double- $\zeta$ plus polarization basis set (SVP).(74) To estimate the effect of the solvent environment on the DFT energies, we used the conductorlike screening model (COSMO) included in TURBOMOLE in which the solvent dielectric continuum is approximated by a scaled conductor.(75) All the DFT calculations were performed in the framework of the multipole accelerated "resolution-of-the-identity" approximation (MARI-J) using the appropriate auxiliary basis set.(76, 77) Note that a dispersion energy correction term was not included in these validation calculations since both the semiempirical QM methods and the PBE gradient-corrected density functional are unable to describe dispersive interactions. 
Both the $\mathrm{Ca}^{2+}$-bound form of the cluster models $\left(\mathbf{C 1}-\mathbf{C a}^{2+}\right.$ and $\left.\mathbf{C 2}-\mathbf{C a}^{2+}\right)$ and the corresponding models in the absence of the $\mathrm{Ca}^{2+}$ ion $(\mathbf{C 1}$ and $\mathbf{C 2})$ were considered in the

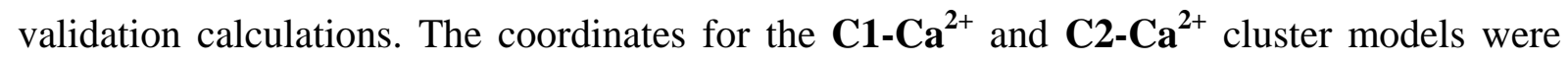
extracted from the $\mathbf{C} \mathbf{a}_{\mathbf{1 - 2}} \mathbf{\&} \mathbf{Z} \mathbf{n}_{\mathbf{1 - 2}}$ MD trajectory while the coordinates for $\mathbf{C} \mathbf{1}$ and $\mathbf{C} 2$ were built using MD snapshots taken from the $\mathbf{C a}_{\mathbf{2}} \mathbf{\&} \mathbf{Z} \mathbf{n}_{\mathbf{1 - 2}}$ and the $\mathbf{C} \mathbf{a}_{\mathbf{1}} \mathbf{\&} \mathbf{Z} \mathbf{n}_{\mathbf{1 - 2}}$ simulations, respectively. A total of 25 snapshots were taken from each MD trajectory. Then the average free energy ( $\Delta \bar{G}_{r x n}$ ) for the following reaction was computed by means of PM3- and DFT-based methodologies:

$$
\mathrm{C1}-\mathrm{Ca}^{2+}{ }_{(\mathrm{aq})}+\mathrm{C} 2_{(\mathrm{aq})} \rightarrow \mathrm{C} 1_{(\mathrm{aq})}+{\mathrm{C} 2-\mathrm{Ca}^{2+}}_{(\mathrm{aq})}
$$

The resulting $\Delta \bar{G}_{r x n}$ values were -36.0 and $-33.6 \mathrm{kcal} / \mathrm{mol}$ at the PM3-PBSA and PBE/SVPCOSMO levels of theory, respectively, the standard error of the mean values being 5.1 and $4.6 \mathrm{kcal} / \mathrm{mol}$. Given that the unsigned difference between the PM3 and DFT values (2.4 $\mathrm{kcal} / \mathrm{mol}$ ) is lower than the statistical imprecision of the individual free energies, we conclude that the semiempirical PM3 method can predict relative free energies for $\mathrm{Ca}^{2+}$ exchange processes comparable to those predicted by the more sophisticated PBE method.

Table S4. Average Values of the PM3 Free Energies (in kcal/mol) and DFT (in au) Free Energies for the Cluster Models representing the $\mathrm{Ca}_{1}$ and $\mathrm{Ca}_{2}$ sites in the MMP-2. Standard Error of the Mean Values is given in Parentheses.

\begin{tabular}{ccccc}
\hline System & \multicolumn{2}{c}{$\mathbf{G ( P M 3}^{\mathbf{a}}$} & \multicolumn{2}{c}{$\left.\mathbf{G}^{\mathbf{a}} \mathbf{D F}\right)^{\mathbf{b}}$} \\
\hline $\mathbf{C 1 - \mathbf { C a } ^ { 2 + }}$ & -1131.5 & $(1.2)$ & -5792.93599 & $(0.00983)$ \\
$\mathbf{C} 2-\mathbf{C a}^{2+}$ & -1058.3 & $(1.3)$ & -6017.51974 & $(0.00669)$ \\
$\mathbf{C} 1$ & -1255.6 & $(1.8)$ & -5115.72040 & $(0.02515)$ \\
$\mathbf{C} 2$ & -1146.4 & $(0.8)$ & -5340.25061 & $(0.01059)$
\end{tabular}

\footnotetext{
${ }^{\mathrm{a}} \overline{\text { From single-point semiempirical calculations on MD snapshots with G(PM3) }=H+\Delta G_{\text {solv }} \text { using DIVCON. See }}$ text for details.

${ }^{\mathrm{b}}$ From single-point PBE/SVP calculations with $G(\mathrm{DFT})=E_{\text {elec }}+\Delta G_{\text {solv }}$ using TURBOMOLE. See text for details.
} 


\section{REFERENCES}

(61) Hoops, S. C., Anderson, K. W., and Merz, K. M. J. (1991) Force field design for metalloproteins. J. Am. Chem. Soc. 113, 8262-8270.

(62) Stote, R. H., and Karplus, M. (1995) Zinc binding in proteins and solution: a simple but accurate nonbonded representation. Proteins: Struct. Funct. Gen. 23, 12-31.

(63) Vedani, A., and Huhta, D. W. (1990) A new force field for modeling metalloproteins. J. Am. Chem. Soc. 112, 4759-4767.

(64) Toba, S., Damodaran, K. V., and Merz, K. M. J. (1999) Binding preferences of hydroxamate inhibitors of the matrix metalloproteinase human fibroblast collagenase. J. Med. Chem. 42, 1225-1234.

(65) Donini, O. A. T., and Kollman, P. A. (2000) Calculation and prediction of binding free energies for the matrix metalloproteinases. J. Med. Chem. 43, 4180-4188.

(66) Maskos, K. (2005) Crystal structures of MMPs in complex with physiological and pharmacological inhibitors. Biochimie 87, 249-263.

(67) Díaz, N., Suárez, D., and Sordo, T. L. (2006) Quantum Chemical Study on the Coordination Environment of the Catalytic Zinc Ion in Matrix Metalloproteinases. $J$. Phys. Chem. B 110, 24222-24230.

(68) (2000), Schrodinger, Inc., Portland, OR.

(69) Becke, A. D. (1995) Exchange-Correlation Approximation in Density-Functional Theory, in Modern Electronic Structure Theory Part II (Yarkony, D. R., Ed.), World Scientific, Singapore.

(70) (1991-2003) in JAGUAR, Schrödinger, L.LC., Portland, OR.

(71) Bayly, C. A., Cieplak, P., Cornell, W. D., and Kollman, P. A. (1993) A Well Behaved Electrostatic Potential Based Method Using Charge Restraints for Deriving Atomic Charges: The RESP model. J. Phys. Chem. 97, 10269-10280.

(72) Ahlrichs, R., Bär, M., Häser, M., Horn, H., and Kölmel, C. (1989) Electronic Structure Calculations on Workstation Computers: The Program System Turbomole. Chem. Phys. Lett. 162, 165-169.

(73) Perdew, J. P., Burke, K., and Ernzerhof, M. (1996) Generalized gradient approximation made simple. Phys. Rev. Lett. 77, 3865-3868.

(74) Schäfer, A., Horn, H., and Ahlrichs, R. (1992) Fully Optimized Contracted Gaussian Basis Sets for Atoms Li to Kr. J. Chem. Phys. 97, 2571-2577. 
(75) Schäfer, A., Klamt, A., Sattel, D., Lohrenzc, J. C. W., and Eckert, F. (2000) COSMO Implementation in TURBOMOLE: Extension of an efficient quantum chemical code towards liquid systems. Phys. Chem. Chem. Phys. 2, 2187-2193.

(76) Eichkorn, K., Treutler, O., Ohm, H., Häser, M., and Ahlrichs, R. (1995) Auxiliary Basis Sets to Approximate Coulomb Potentials. Chem. Phys. Lett. 242, 652-660.

(77) Sierka, M., Hogekamp, A., and Ahlrichs, R. (2003) Fast evaluation of the Coulomb potential for electron densities using multipole accelerated resolution of identity approximation. J. Chem. Phys. 118, 9136-9148. 
Figure S1. Ball-and-stick representation of the cluster models considered in the validation QM calculations.

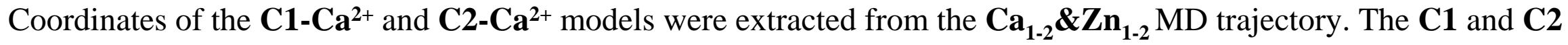
models were built using MD snapshots taken from $\mathbf{C a}_{\mathbf{1}} \mathbf{\&} \mathbf{Z n}_{\mathbf{1 - 2}}$ and the $\mathbf{C a}_{\mathbf{2}} \mathbf{\&} \mathbf{Z} \mathbf{n}_{\mathbf{1 - 2}}$, respectively.
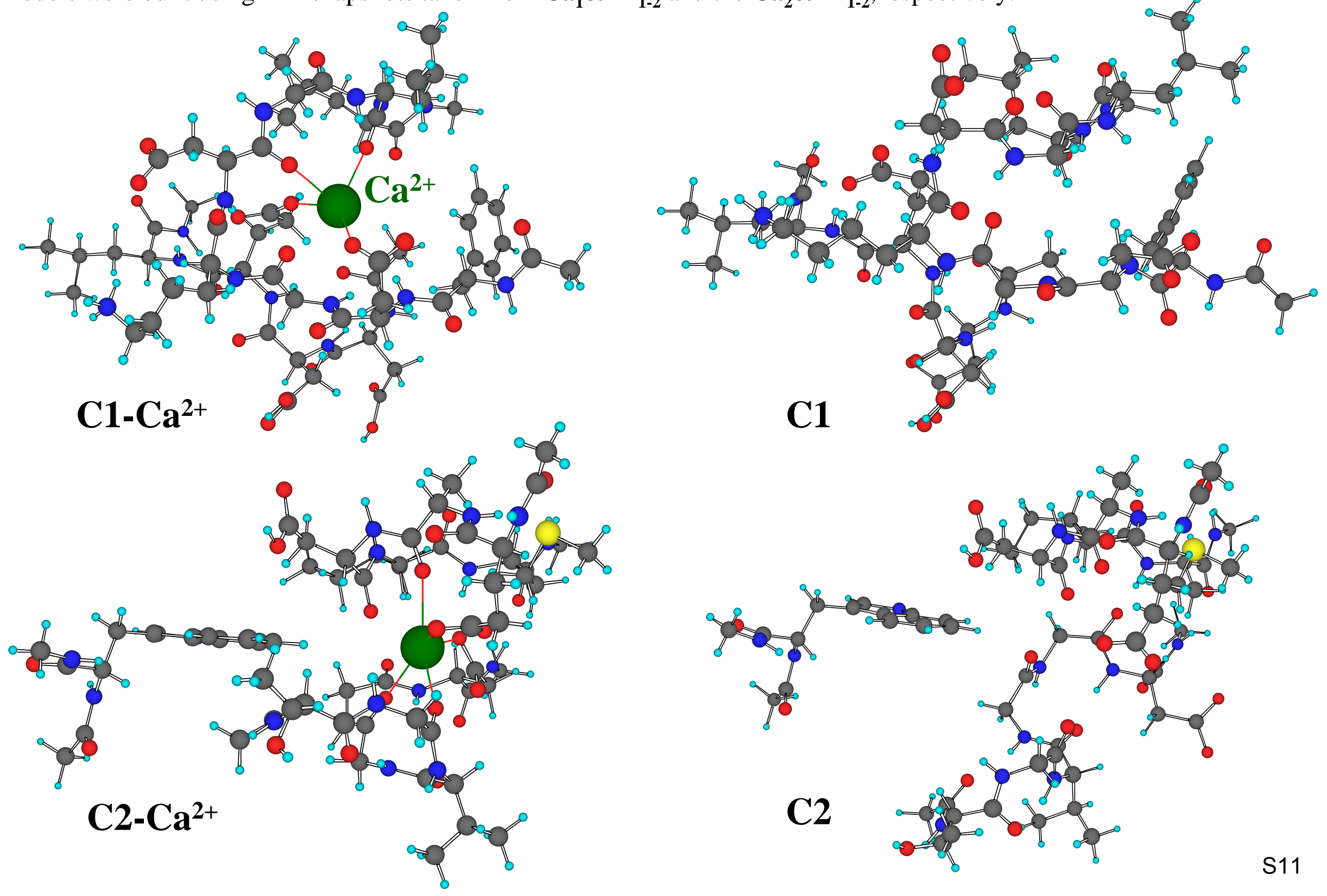
Figure S2. Electrostatic potential mapped onto the MSMS molecular surface for the MMP-2 models. The orientation of the MMP-2 molecules as in Figure 1. Red indicates negative potential and blue is positive potential.

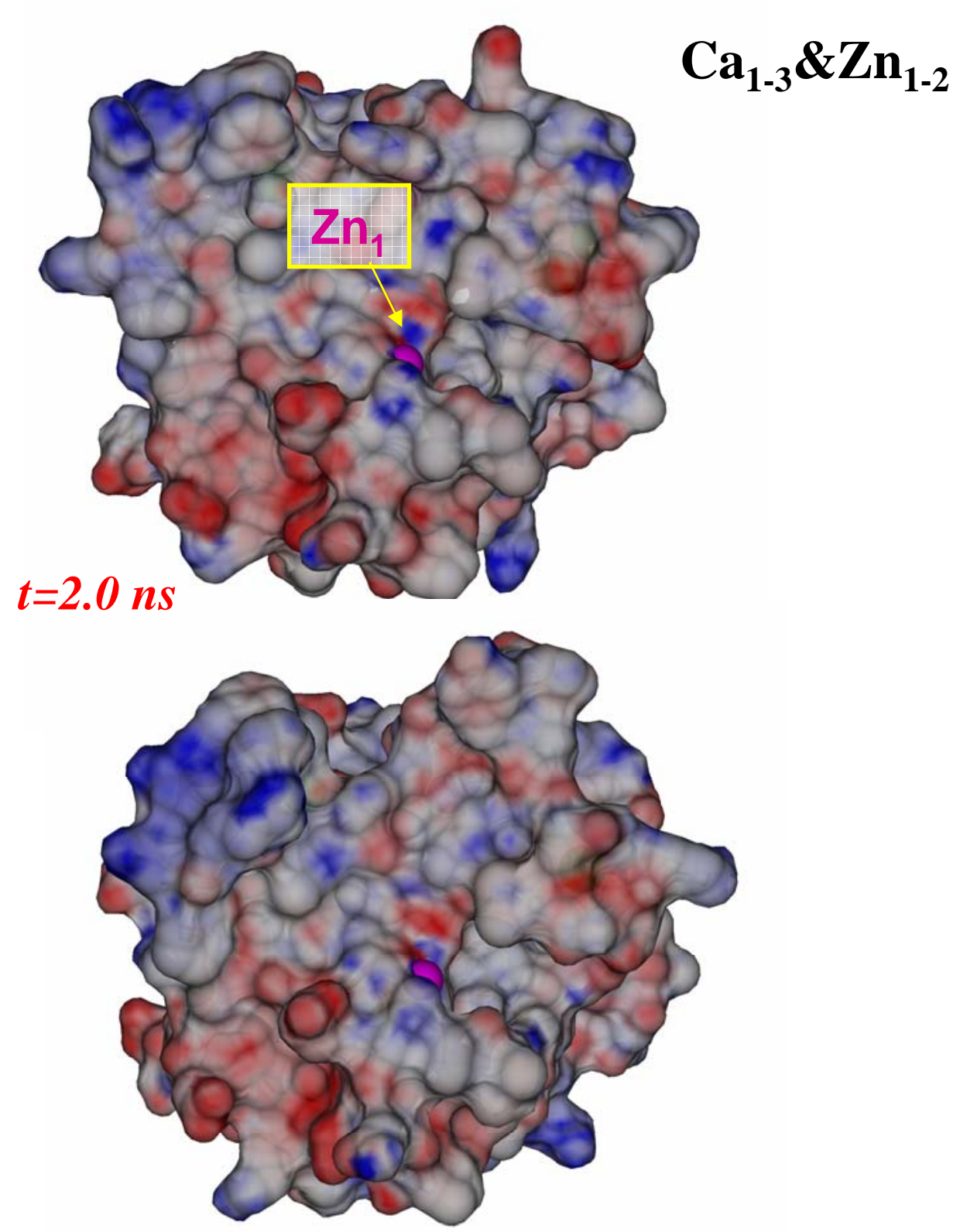

$t=6.0 \mathrm{~ns}$
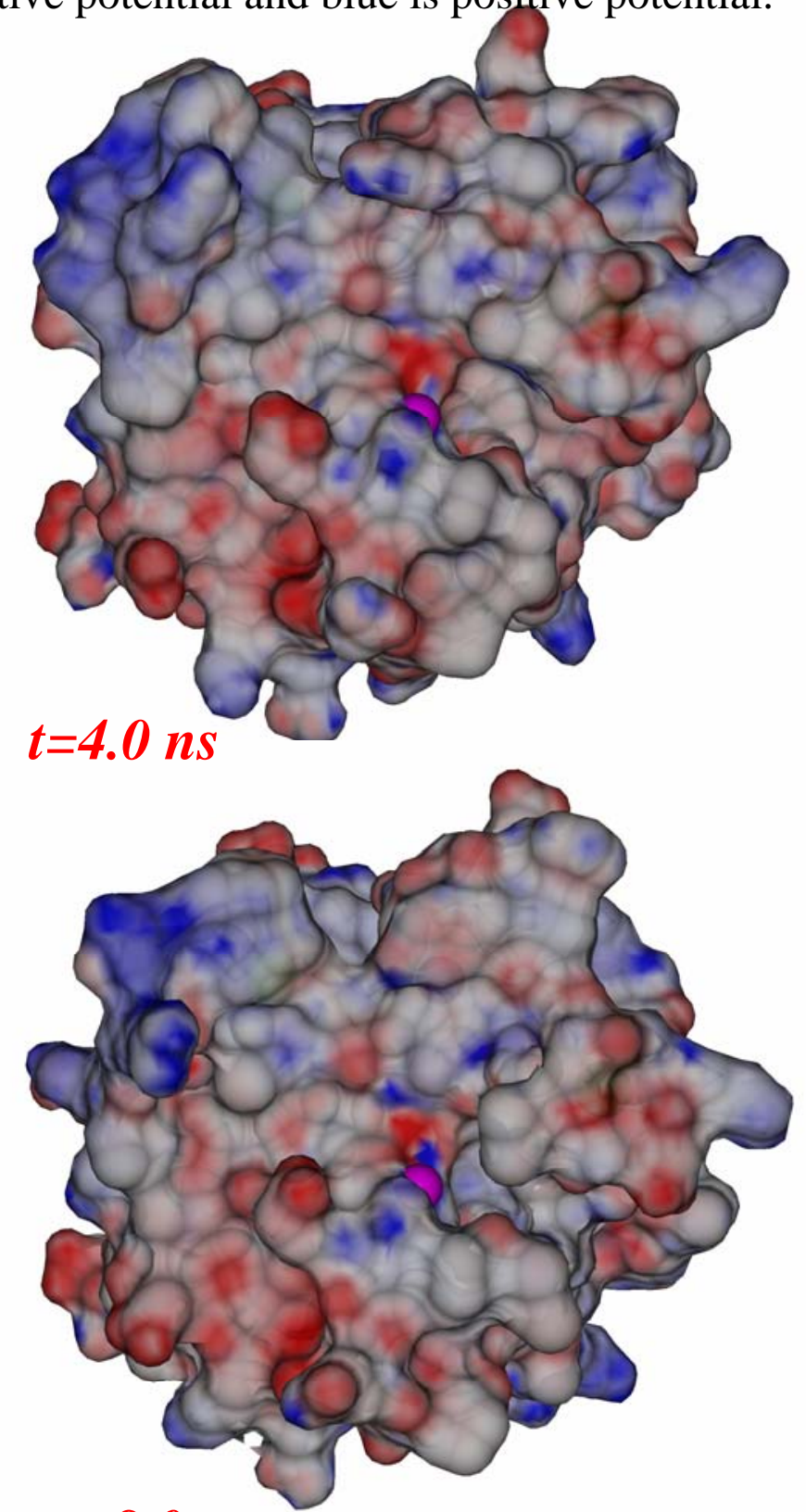

$t=8.0$ ns 
Figure S2 (cont.)
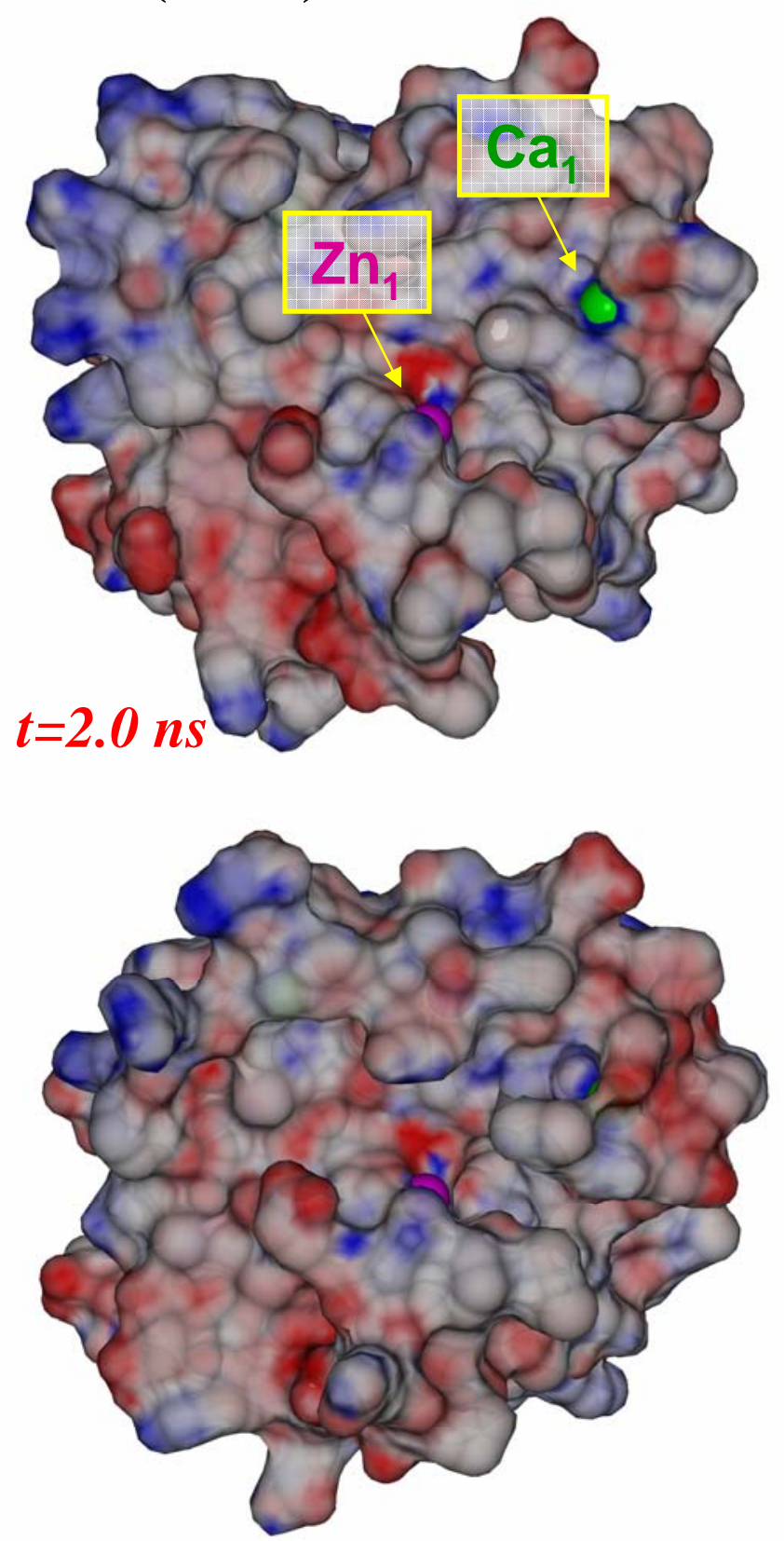

$t=6.0$ ns
$\mathrm{Ca}_{1-2} \& \mathrm{Zn}_{1-2}$
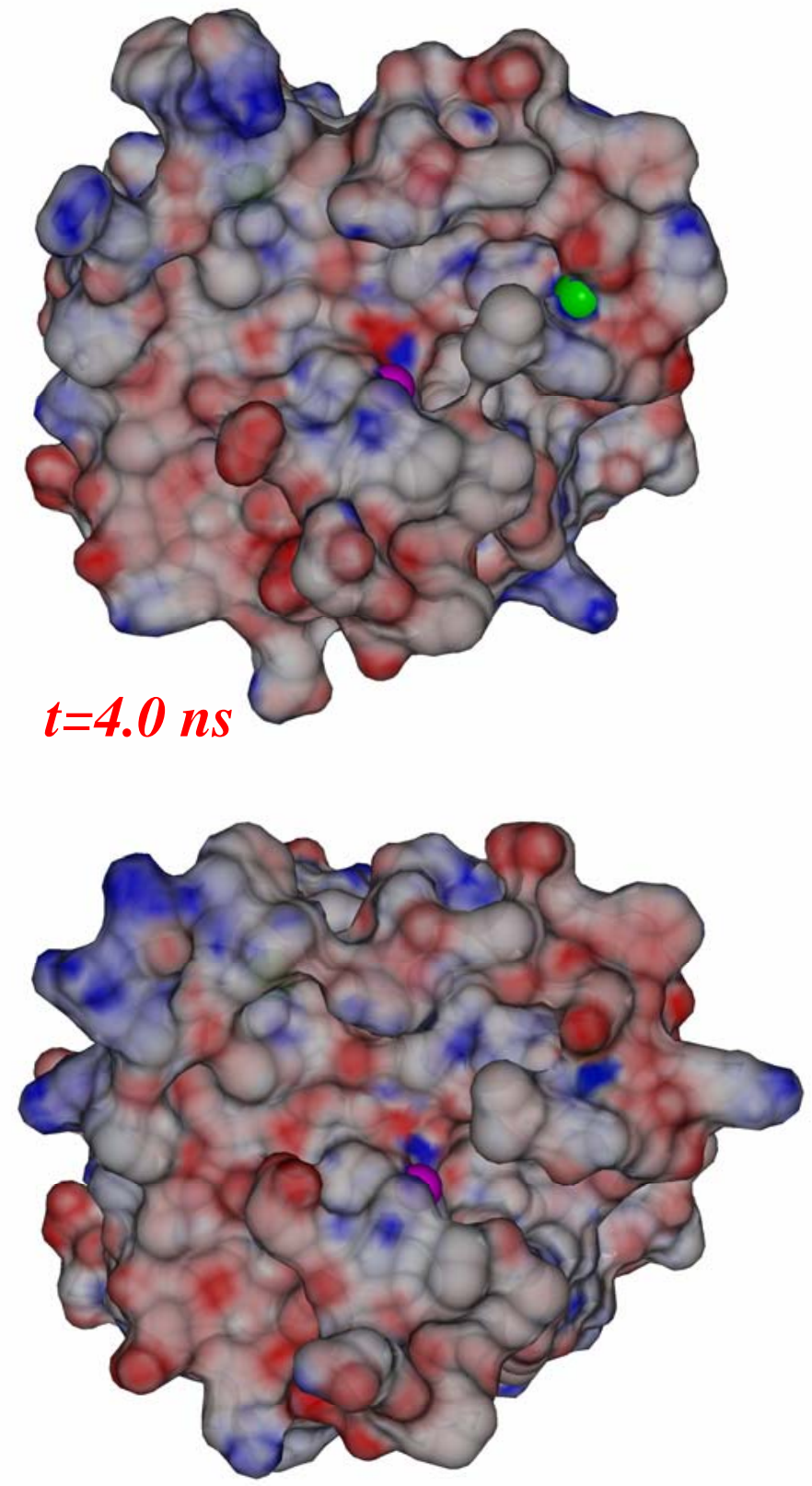

$t=8.0$ ns 
Figure S2 (cont.)
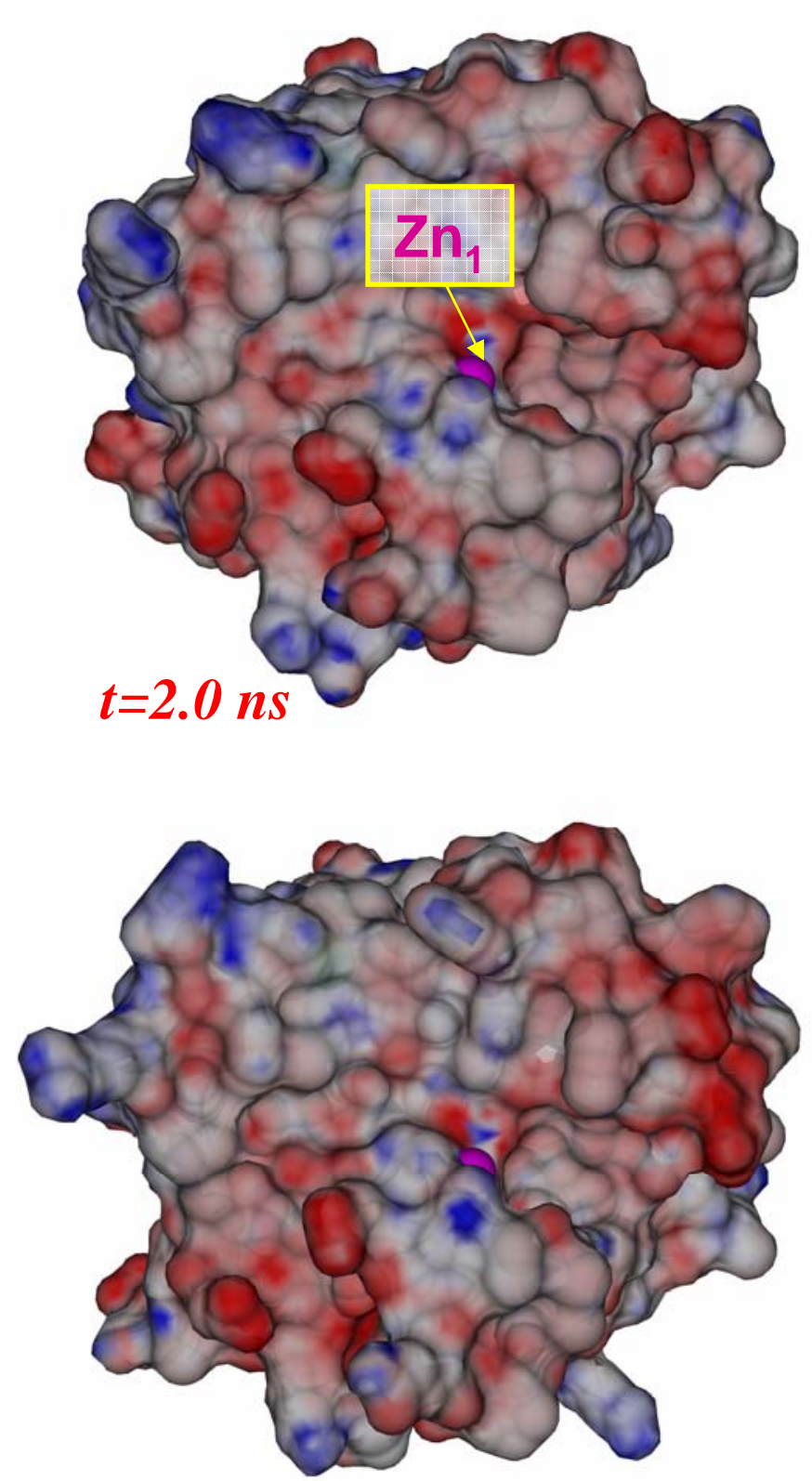

$t=6.0$ ns
$\mathrm{Ca}_{2} \& \mathrm{Zn}_{1-2}$

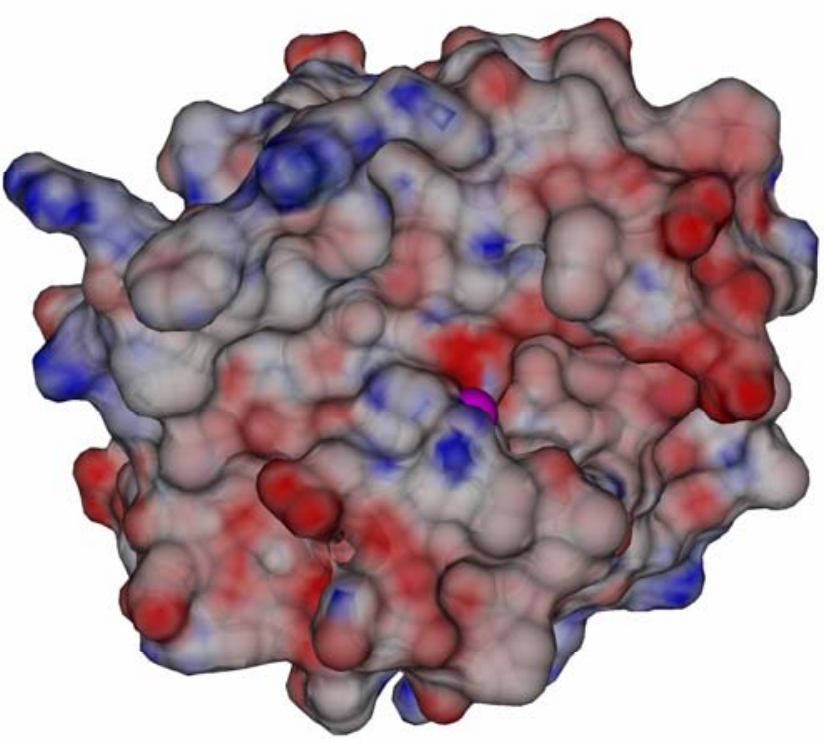

$t=4.0$ ns

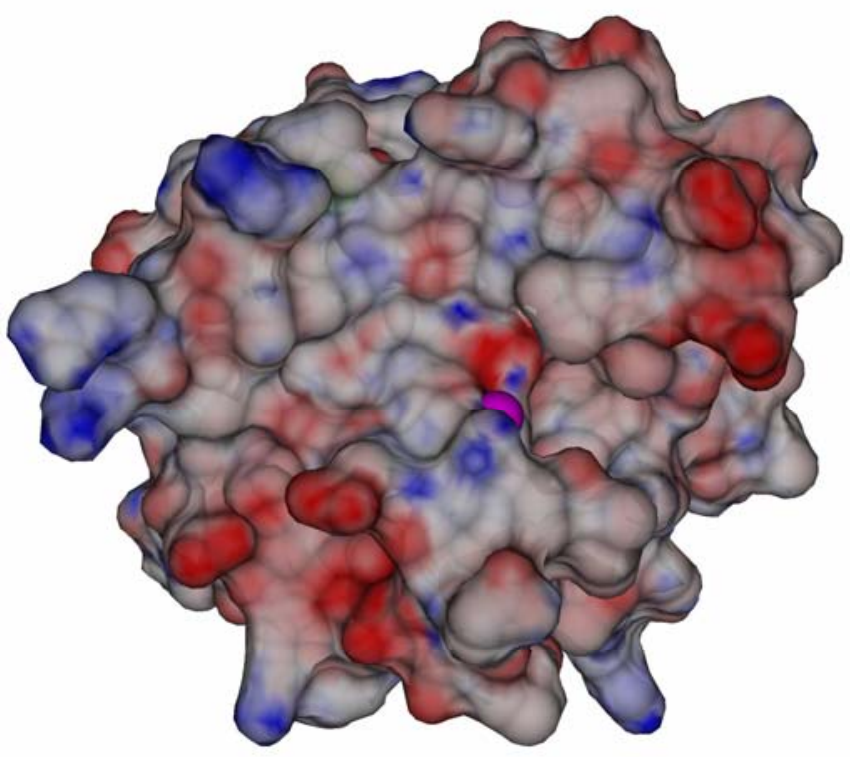

$t=8.0$ ns 
Figure S2 (cont.)
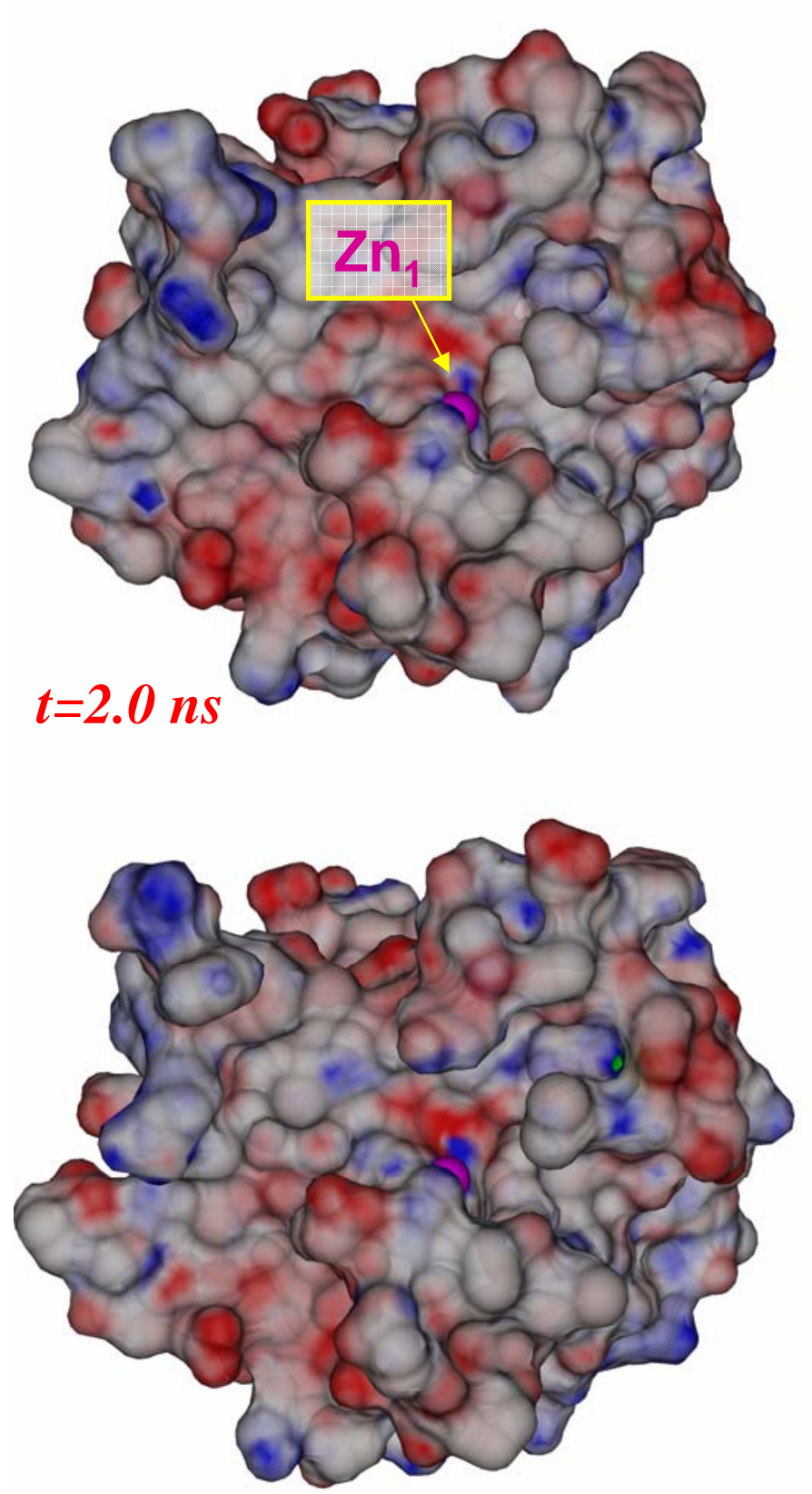

$t=6.0 \mathrm{~ns}$
$\mathrm{Ca}_{1} \& \mathrm{Zn}_{1-2}$
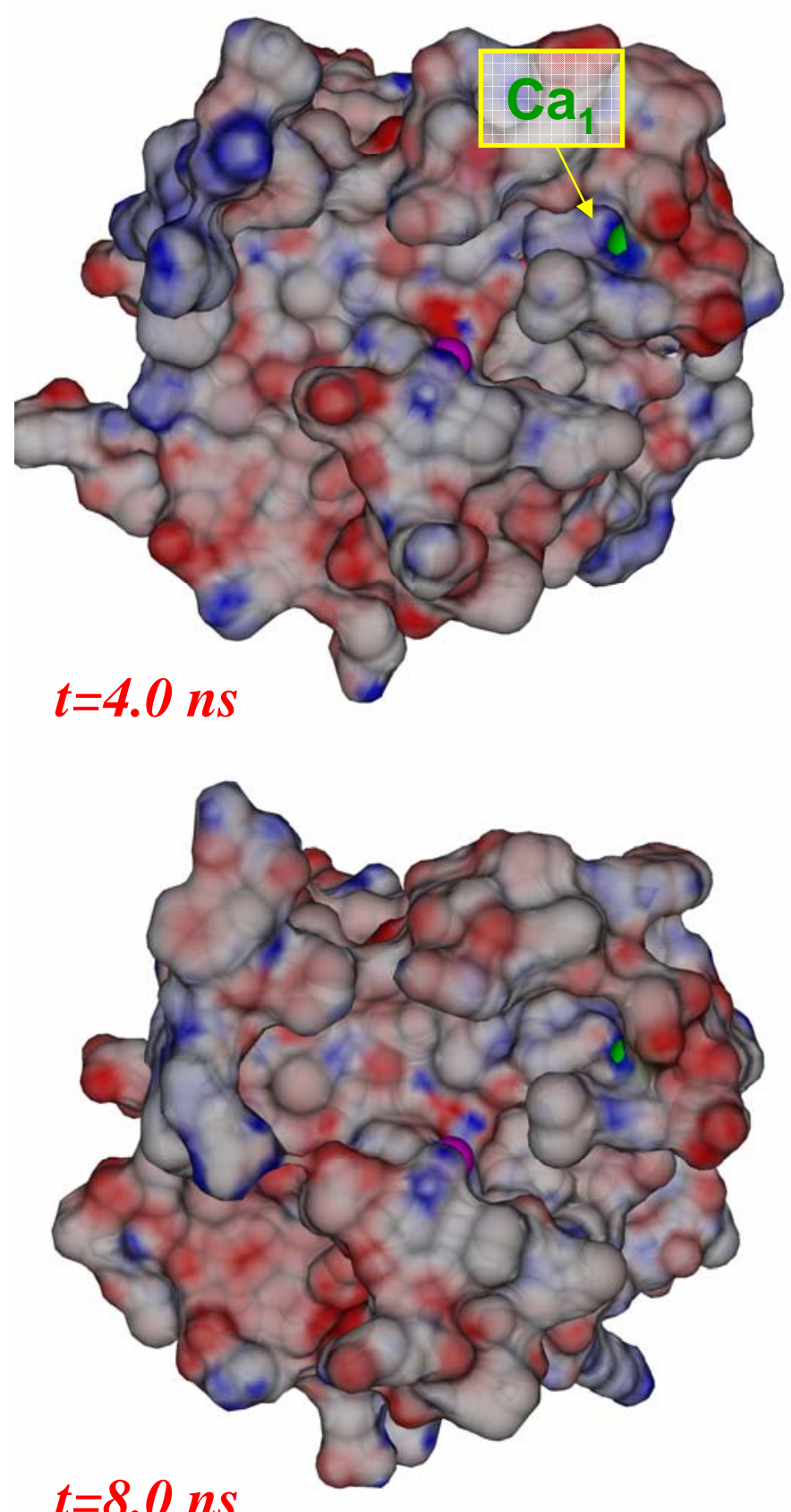
Figure S2 (cont.)
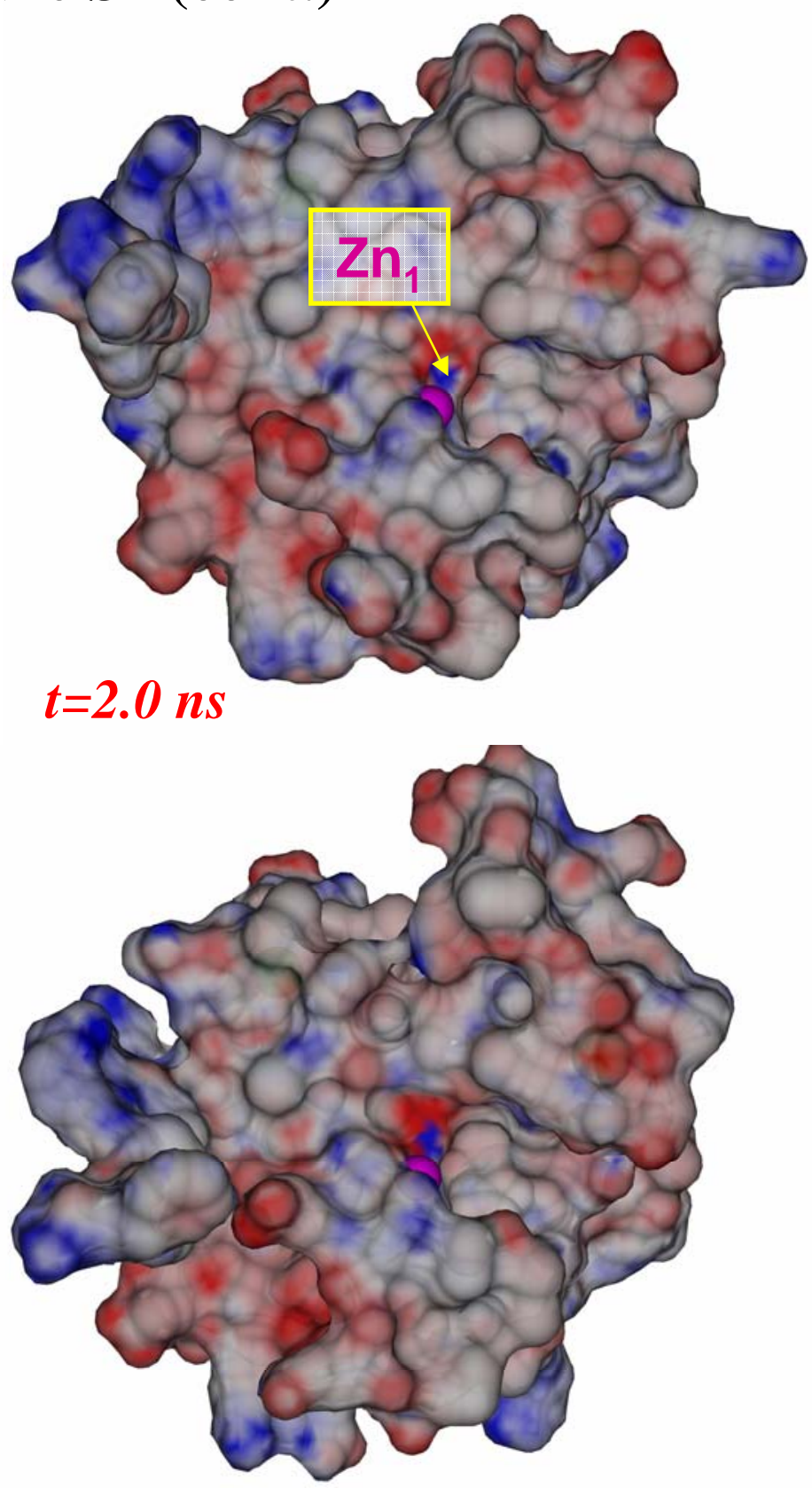

$t=6.0$ ns

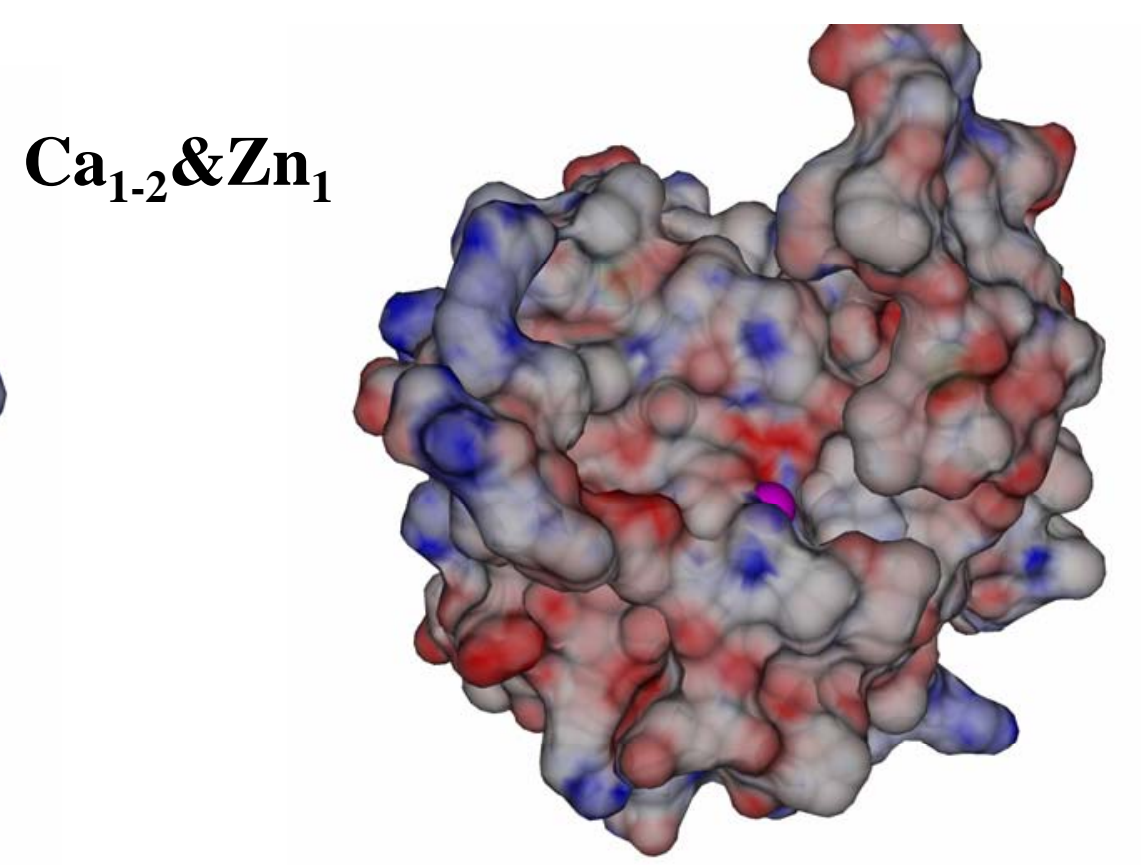

$t=4.0$ ns

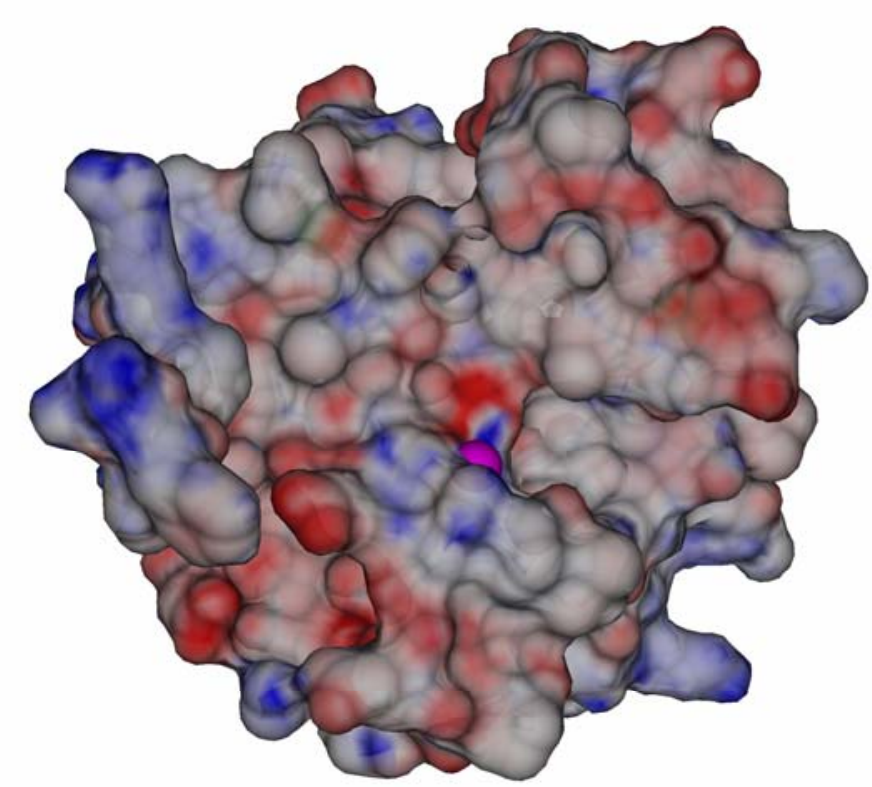

$t=8.0$ ns 
Figure S2 (cont.)

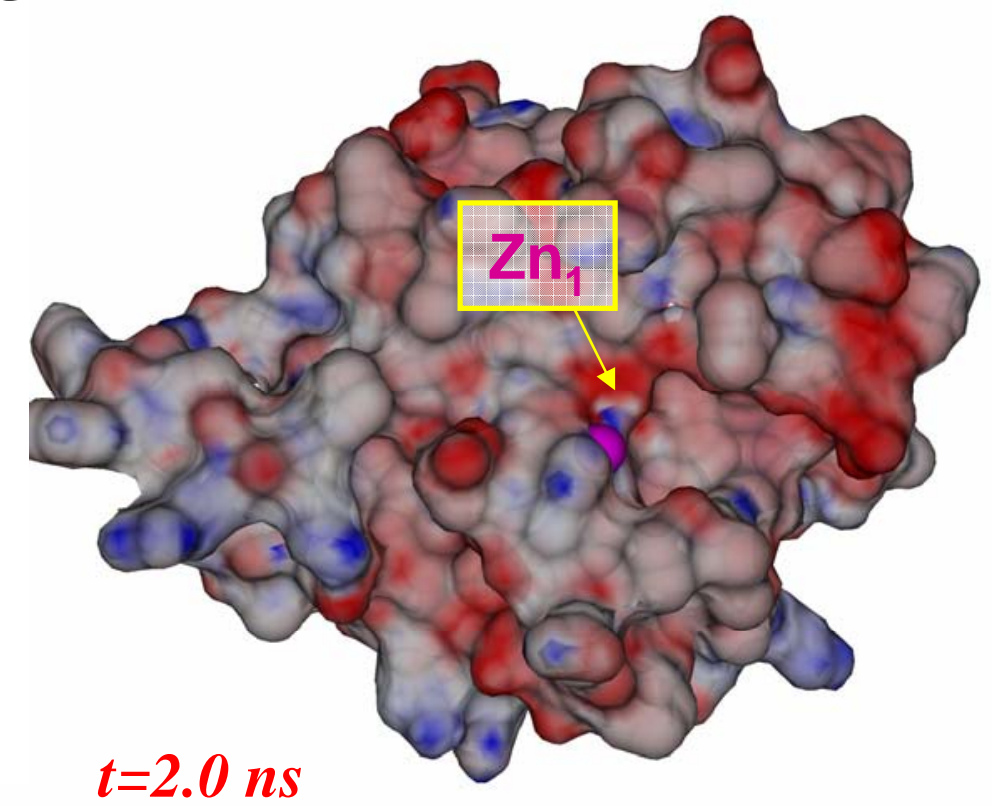

$\mathrm{Zn}_{\text {1-2 }}$

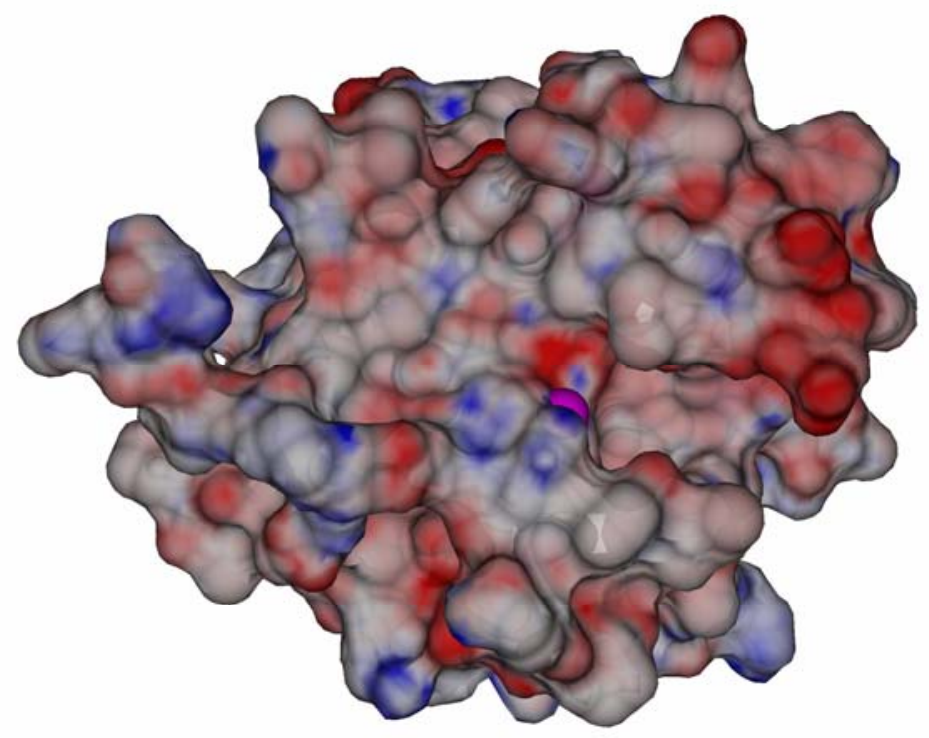

$t=6.0 \mathrm{~ns}$
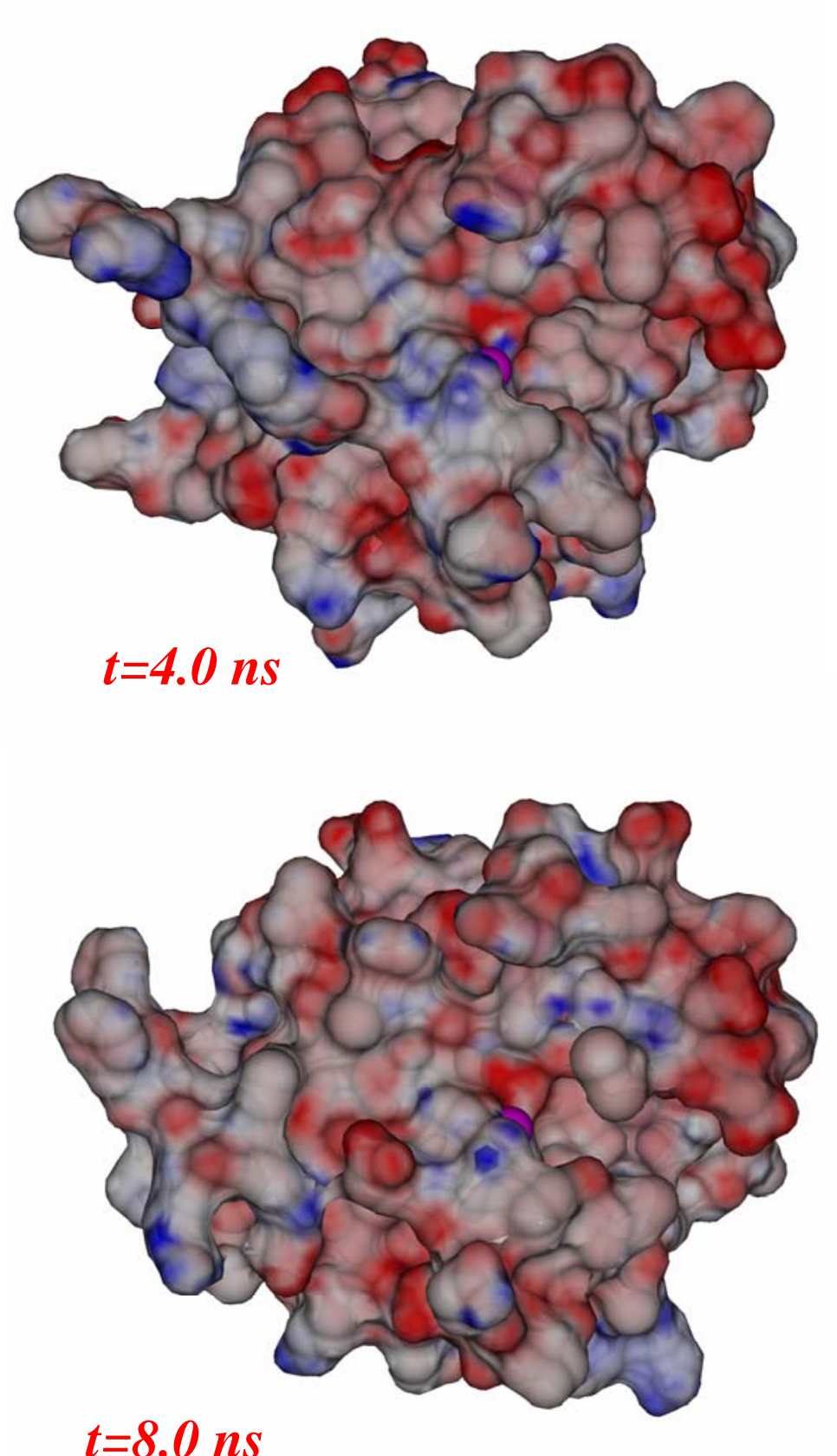
Figure S2 (cont.)

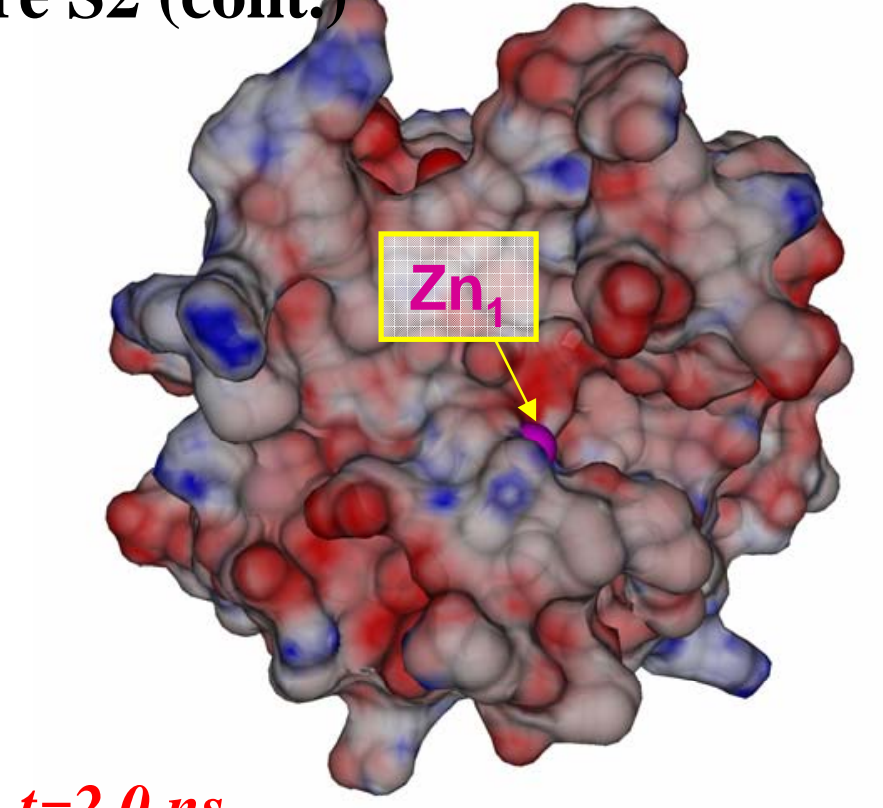

$t=2.0$ ns

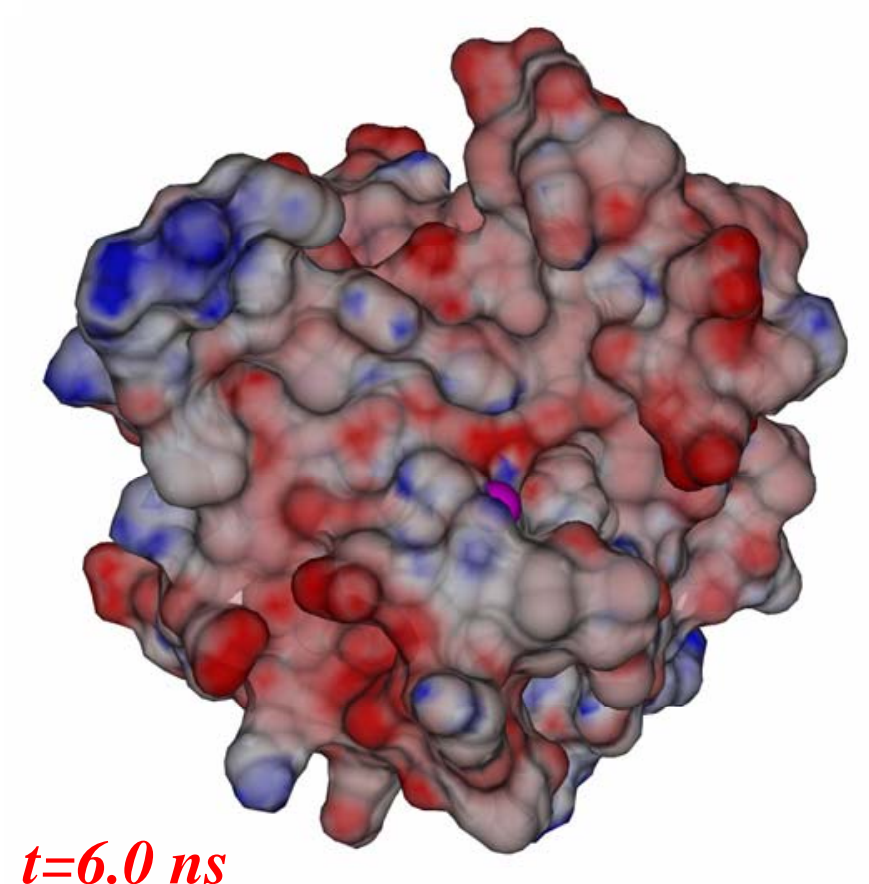

$\mathbf{Z n}_{1}$

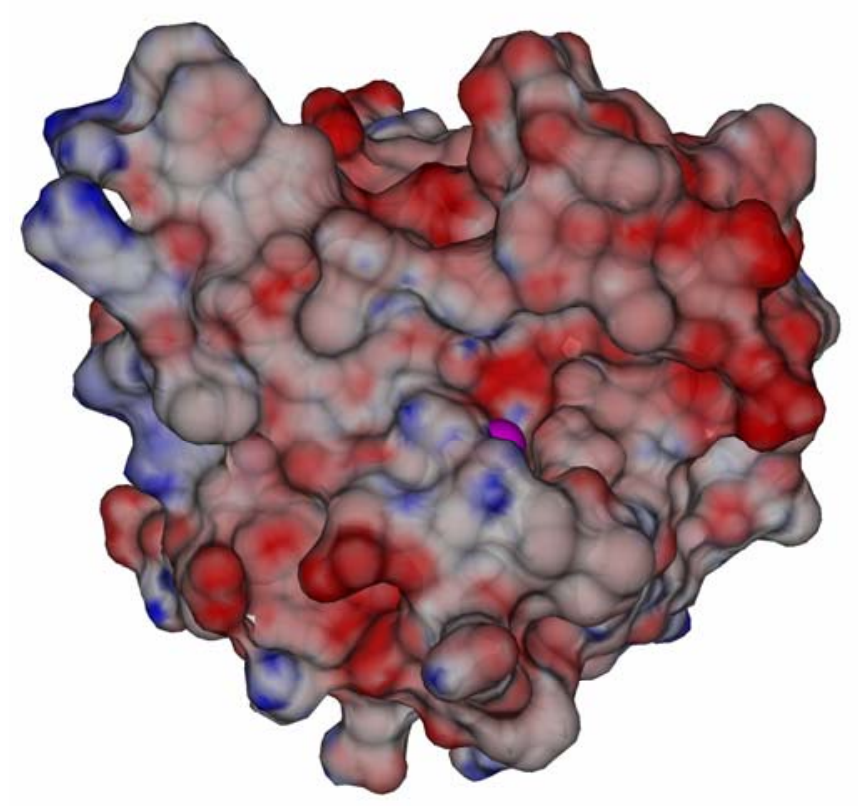

$t=4.0$ ns

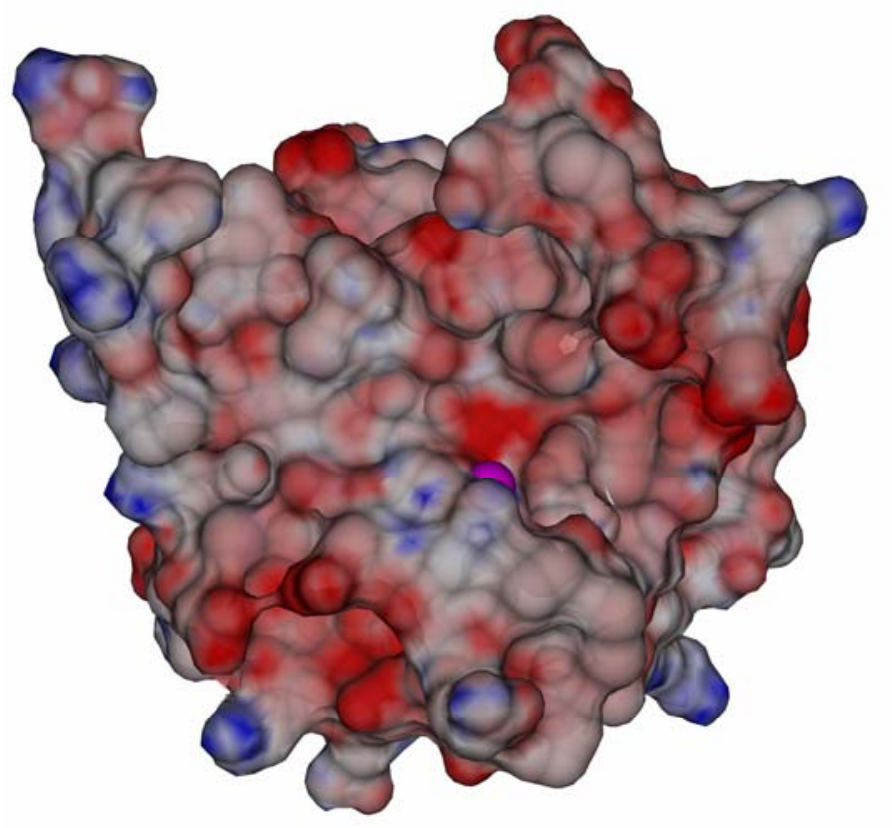

$t=8.0$ ns 